\title{
Mentally ill patients who were accompanied and those who weren't on their first visit to the Mental Health Center of Peristeri Panagiotis Papadopoulos*, Efstathios Panagoulias and Magda Stergioula
}

\author{
Address: Mental Health Center of Peristeri, Athens, Greece
}

* Corresponding author

from International Society on Brain and Behaviour: 3rd International Congress on Brain and Behaviour

Thessaloniki, Greece. 28 November - 2 December 2007

Published: 17 April 2008

Annals of General Psychiatry 2008, 7(SuppI I):SI 25 doi:I0.II86/I744-859X-7-SI-SI 25

This abstract is available from: http://www.annals-general-psychiatry.com/content/7/SI/SI 25

(c) 2008 Papadopoulos et al.; licensee BioMed Central Ltd.

\section{Background}

The purpose of this study was to spot differences between the two above groups in relation to a variety of demographic and clinical variables.

\section{Materials and methods}

285 patients took part in this study.

45 of them were accompanied whereas 240 weren't. All these patients visited our Center during 2003. This year was chosen randomly. Several variables were examined such as: sex, age, educational level, family status and diagnosis.

\section{Results}

In both groups the women dominated in number in relation to the men. As for the educational level those who finished high school dominated in both groups.

The average age of both groups was about 34 although it differentiated completely between the sexes.

Something else that is worth noting is the predominance of married patients in the group of non-accompanied in contrast to the other group.

Finally, in relation to the diagnosis, the patients with psychosis and secondarily those with affective disorders predominated in the group of accompanied patients in contrast with the other group where the predominated patients were those with affective disorders and secondarily with anxiety disorders.

\section{Conclusions}

From the results it seems that the most influencial variables in creating the prementioned groups of patients are those of family status and diagnosis.

The predominance of the unmarried psychotic patients in the group of accompanied patients in contrast to those who were married and with affective-anxiety disorders in the other group of non accompanied ones, seems to be logical. 